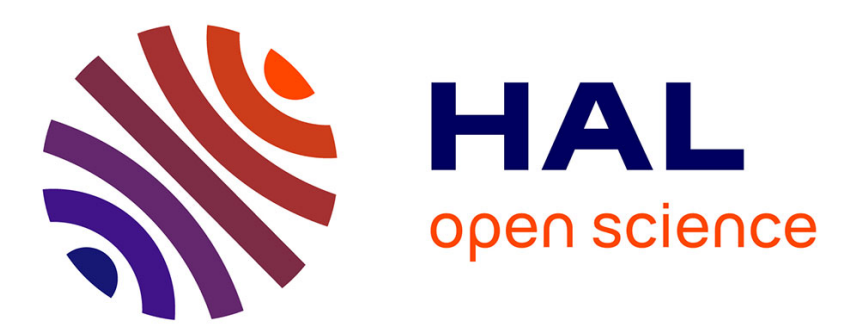

\title{
Topological aspects of oligomeric UDP-glucuronosyltransferases in endoplasmic reticulum membranes: advances and open questions
}

\author{
Karl Walter Bock, Christoph Köhle
}

\section{- To cite this version:}

Karl Walter Bock, Christoph Köhle. Topological aspects of oligomeric UDP-glucuronosyltransferases in endoplasmic reticulum membranes: advances and open questions. Biochemical Pharmacology, 2009, 77 (9), pp.1458. 10.1016/j.bcp.2008.12.004 . hal-00493477

\section{HAL Id: hal-00493477 https://hal.science/hal-00493477}

Submitted on 19 Jun 2010

HAL is a multi-disciplinary open access archive for the deposit and dissemination of scientific research documents, whether they are published or not. The documents may come from teaching and research institutions in France or abroad, or from public or private research centers.
L'archive ouverte pluridisciplinaire HAL, est destinée au dépôt et à la diffusion de documents scientifiques de niveau recherche, publiés ou non, émanant des établissements d'enseignement et de recherche français ou étrangers, des laboratoires publics ou privés. 


\section{Accepted Manuscript}

Title: Topological aspects of oligomeric

UDP-glucuronosyltransferases in endoplasmic reticulum

membranes: advances and open questions

Authors: Karl Walter Bock, Christoph Köhle

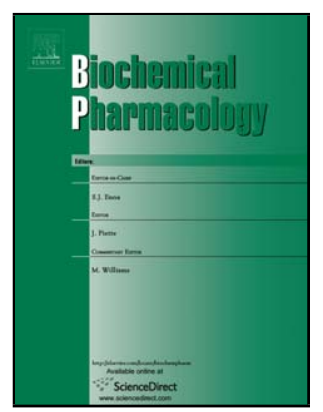

PII:

S0006-2952(08)00891-5

DOI:

doi:10.1016/j.bcp.2008.12.004

Reference:

BCP 10036

To appear in: $\quad B C P$

Received date: $\quad 27-10-2008$

Revised date: $\quad 4-12-2008$

Accepted date: $\quad 9-12-2008$

Please cite this article as: Bock KW, Köhle C, Topological aspects of oligomeric UDPglucuronosyltransferases in endoplasmic reticulum membranes: advances and open questions, Biochemical Pharmacology (2008), doi:10.1016/j.bcp.2008.12.004

This is a PDF file of an unedited manuscript that has been accepted for publication. As a service to our customers we are providing this early version of the manuscript. The manuscript will undergo copyediting, typesetting, and review of the resulting proof before it is published in its final form. Please note that during the production process errors may be discovered which could affect the content, and all legal disclaimers that apply to the journal pertain. 
Topological aspects of oligomeric UDP-glucuronosyltransferases in endoplasmic reticulum membranes: advances and open questions

Karl Walter Bock* and Christoph Köhle

Department of Toxicology, Institute of Pharmacology and Toxicology, University of Tübingen, Germany

Running title: Topological aspects of oligomeric UGTs

Abbreviations: BaP, benzo[a]pyrene; ER, endoplasmic reticulum; 3-MC, 3methylcholanthrene; ROS, reactive oxygen species; T4, thyroxine; UDPGA, UDPglucuronic acid; UGT, UDP-glucuronosyltransferase

*Corresponding author. Tel.: +49 7071 2972274; fax: +49 7071292273.

E-mail address: bock@uni-tuebingen.de (K.W. Bock). 


\begin{abstract}
UDP-glucuronosyltransferases (UGTs) represent major Phase II enzymes involved in detoxification of endo- and xenobiotics, including many drugs. The intraluminal orientation of the active site of UGTs in endoplasmic reticulum membranes necessitates a number of transporters in these membranes, for example, for UDPglucuronic acid and glucuronides, the latter being insufficiently characterized. In addition, accumulating evidence suggests that UGTs are functional as homo- and hetero-dimers in monoglucuronide formation. They may form tetramers in diglucuronide formation. UGT oligomers probably serve to stabilize UGT monomers and fine-tune UGT activity. Glucuronide disposition may also be influenced by endoplasmic reticulum-localized $\beta$-glucuronidase, possibly involved in hydrolysis of hormone and drug glucuronides in target cells. The present commentary reviews recent advances and addresses open questions. Resolution of these questions may help to understand many problems of glucuronide synthesis and disposition in vivo, for example, under-prediction of the in vivo clearance of drugs mostly eliminated by glucuronidation by in vitro enzyme kinetic parameters of UGTs.
\end{abstract}

Key words: UDP-glucuronosyltransferases; UGT topology in endoplasmic reticulum membranes; UGT oligomers; diglucuronide formation; $\beta$-glucuronidase. 


\section{Introduction}

Glucuronidation represents a major Phase II biotransformation reaction. It is catalyzed by two evolutionary conserved UGT enzyme families, each including at least 8 enzymes which are adaptively regulated in a tissue-specific manner [1-5]. The review by Geoffrey Dutton [1] represents an invaluable source of the earlier literature. UGTs are involved in detoxification of endobiotics including bilirubin, thyroxine, steroids, and xenobiotics including phytochemicals, carcinogenic polycyclic hydrocarbons and a variety of prescribed drugs from all therapeutic classes. The intraluminal orientation of the active site of UGTs and of $\beta$-glucuronidase in ER membranes necessitates a number of transporters in these membranes. Following transport of glucuronides between ER lumen and cytosol, conjugate transporters in the plasma membrane are required to prevent the accumulation of polar conjugates in cells [6-8]. Recently, accumulating evidence suggests that UGTs are functional in ER membranes as dimeric complexes, and may form tetramers in diglucuronide formation. The present commentary reviews recent advances and addresses open questions about the UGT topology in ER membranes and their oligomeric nature. Glucuronide disposition may be influenced by ER-localized $\beta$-glucuronidase, possibly involved in futile cycling of glucuronides and hydrolysis of hormone and drug glucuronides in target cells. Resolution of these questions may help to understand many problems of glucuronide synthesis and disposition in vivo, for example underprediction of the in vivo clearance of drugs mostly eliminated by glucuronidation by in vitro enzyme kinetic parameters of UGTs.

\section{Topology of UGTs in ER membranes}

A number of advances have recently been made on the structure and topology of UGTs and $\beta$-glucuronidase in ER membranes (Fig. 1). The schematic representation should be viewed as an extension of the previously published hypothetical model of UGT dimers [4]. UGTs are integral ER membrane proteins with a transmembrane segment and a short cytoplasmic tail. They are known to be active at the luminal side of the ER [3,4]. This topology necessitates recently identified nucleotide sugar transporters (NSTs) to carry the cofactor UDP-glucuronic acid (UDPGA) to the ER lumen [9]. They act as antiporters requiring countertransport of UDP-Nacetylglucosamine [10]. The reason for luminal orientation of UGTs is unknown but 
may be due to evolutionary constraints since many glycosyltransferase reactions including those involved in glycoprotein synthesis occur in the ER lumen. UGT monomers consist of the $\mathrm{N}$-terminal aglycone substrate-binding half of the protein and the UDP-glucuronic acid-binding C-terminus, the latter containing one transmembrane sequence [2-4]. The crystal structure of the UDPGA-binding Cterminal half of UGT2B7 has recently been determined at 1.8-A resolution. Mutants at residues predicted to interact with UDPGA exhibited impaired catalytic activity, and mutants at predicted aglycone binding sites abrogated UGT activity [11]. In addition, an internal signal sequence has been identified embedding part of the $\mathrm{N}$-terminal half of UGTs in the ER membrane, a feature which may facilitate access of lipophilic aglycones to the active site [12].

UGTs conjugate glucuronic acid to functional groups of a variety of aglycones mostly hydroxyl, amino or carboxyl groups. With hydroxyl groups $(\mathrm{XOH})$ they catalyze the following reversible reaction: $\mathrm{XOH}+\mathrm{UDPGA} \leftrightarrows \mathrm{XOGA}+\mathrm{UDP}$. Recent extensive kinetic analysis in microsomal preparations in vitro suggested an ordered bi bi mechanism in which the aglycone substrate may act as an inhibitor by binding to the enzyme-UDP complex and thus depleting the active enzyme pool [13]. However, the reversible reaction may only rarely occur in the intact cell since the two products of the UGT reaction are rapidly removed: (i) UDP is rapidly hydrolyzed to UMP by nucleoside diphosphatase in the hepatic ER lumen [14]. Rapid hydrolysis of UDP in microsomes may explain the lack of UDP-dependent inhibition of UGT reactions in liver microsomes in contrast to preparations from expressed UGTs [15]. (ii) Glucuronides appear to be rapidly translocated to the cytosol. Evidence for multiple ER-localized organic anion transporters $\left(A T_{E R}\right)$ has been obtained which - in contrast to plasma membrane-localized ATP-dependent glucuronide transporters - do not need ATP but transport organic anions through ER membranes by facilitated diffusion $[16,17]$. Some of these transporters may also be involved in transport of hormone glucuronides such as thyroxine glucuronide from the cytoplasm to ERlocalized $\beta$-glucuronidase (see chapter 5.3).

\section{Monoglucuronide formation by UGT dimers}

Accumulating evidence suggests that UGTs mostly operate as dimeric complexes. Using mutants and chimeric constructs Meech and Mackenzie demonstrated that 
oligomerization of two inactive mutants could yield an active unit [18]. Nearest

neighbor crosslinking studies followed by gel filtration provided evidence that UGTs form dimers in microsomes $[19,20]$. Using a variety of techniques evidence was obtained that oligomers may function as homo- $[20,21]$ or hetero-oligomers [21-25]. For example, in live cells intermolecular interactions among UGT1A proteins was demonstrated by fluorescently tagged UGT1A proteins and homo- and heterodimerization by co-immunoprecipitation analysis [21]. Cotranslational insertion of UGTs into the membrane appears to be a requirement for oligomerization [21]. UGTs as oligomeric enzymes were critically discussed [23]. Functional implications of dimer formation were studied in several ways: for example, co-expression of an inactive mutant of UGT1A6 (the only enzyme catalyzing serotonin glucuronidation [26]) and of UGT1A4 restored UGT1A6-mediated serotonin glucuronidation, suggesting tight interaction between the two recombinant enzymes. Interestingly, these dimers did not share substrate binding sites [23,24]. Heterodimerization has been shown to up- or down-regulate UGT activity [25]. In addition, heterodimers may include recently identified inhibitory UGTs [27]. However, more work is needed to characterize these homo- and hetero-oligomers and their functional implications.

\section{Diglucuronide formation by UGT tetramers}

Some UGT dimers may form tetramers as suggested by radiation target analysis, a method which has been conceptually and experimentally established by Ellis Kempner, and frequently applied to determine the functional molecular mass of membrane proteins [28-30]. Studies of bilirubin glucuronidation suggested that diglucuronide formation may be carried out by UGT tetramers [31]. Expressed human UGT1A1 efficiently converts the two bilirubin monoglucuronides (at either the $\mathrm{C} 8$ or C12 propionic acid group) to the diglucuronide [32], and bilirubin is known to be mainly secreted in human bile as the diglucuronide.

Radiation inactivation analysis was also carried out in studies of 3,6-quinol monoglucuronide (MG) and diglucuronide (DG) formation of $\mathrm{BaP}$ and the chemically more stable chrysene (Fig.2). We got interested in these reactions because of strong induction of these UGT activities in hepatic microsomes from 3-MC-treated rats [33,34]. Induction factors were 10- and 40-fold for BaP-3,6-quinol MG and DG 
formation, and 7- and 310-fold for chrysene MG and DG formation, respectively. 3MC-inducible UGT1A7 efficiently converted the studied quinol monoglucuronides to their diglucuronides [35], as suggested by much lower MG/DG ratios compared to microsomes from untreated controls (Table 1). However, enzyme induction alone may not explain the efficiency of DG formation. For example, 3-MC treatment of rats enhanced chrysene-3,6-DG formation about 310-fold in liver microsomes, suggesting - in addition to induction of UGT isoforms- an influence of topological features of UGT quaternary structure, discussed subsequently. Glucuronidation of quinols is toxicologically relevant since it probably prevents quinone-quinol redox cycles and associated oxidative stress [33-37]. BaP quinol diglucuronides represent major conjugates in bile and urine after administration of $\mathrm{BaP}[38,39]$.

Radiation inactivation analysis was carried out using the described quinol MG and DG reactions [40]. For monoglucuronide formation of BaP- and chrysene-3,6-quinol target sizes were $118 \pm 33$ and $109 \pm 21 \mathrm{kDa}$, respectively (in agreement with the existence of dimers) whereas for diglucuronide formation target sizes were $218 \pm 24$ and $192 \pm 34 \mathrm{kDa}$, respectively, suggesting the formation of tetramers. It should be noted that in early enzyme purification studies, gel filtration in presence of detergents revealed peaks at the position of tetrameric UGT complexes [41,42]. In diglucuronide formation some dimers may loosely interact in ER membranes to form tetramers (Fig. 1), findings which, however, need further validation. Loose interaction may explain why tetramers have not been detected in cross-linking studies [20]. Nevertheless, as discussed previously [23], high molecular weight bands possibly corresponding to tetramers can be seen by close inspection of the cross-linking studies of Gosh et al. [20 (Fig. 3, lane 3 and 4)]. Tetramers may generate a compartment between two dimers in which monoglucuronides reach high levels to facilitate diglucuronide formation, as evidenced in studies on BaP-3,6-quinol diglucuronide formation: while a high $K_{M}$ value $(>70 \mu M)$ was detected when the diglucuronide was formed from synthesized monoglucuronides, a much lower $\mathrm{K}_{\mathrm{M}}$ of 10-20 $\mu \mathrm{M}$ was determined when starting the reaction from the quinol $[43,44]$. However, it is acknowledged that the results could also reflect the ease of access of quinols versus quinol glucuronide across the ER membrane. Radiation target analysis of bilirubin glucuronidation using human microsomes and expressed UGT1A1 may be useful to substantiate formation of UGT tetramers. 


\section{In vitro-in vivo comparison of glucuronide formation}

To guide future studies on synthesis and hydrolysis of glucuronides in ER membranes, the relevance of UGT activity is emphasized (i) by correlation studies using UGT polymorphism UGT1A1*28, and (ii) by comparative studies between in vitro kinetic parameters of UGTs and in vivo clearance of drugs mostly eliminated by glucuronidation.

\subsection{Bilirubin UGT polymorphism UGT1A1*28}

Allelic variants often clearly demonstrate the relevance of proteins. Functional UGT polymorphisms are increasingly identified, and are updated in the UGT web site at http://som.flinders.edu.au/FUSA/ClinPharm/UGT. It is assumed that further analysis of bilirubin mono- and diglucuronide formation may help to answer open questions on UGT oligomers. Therefore, in vivo findings using the frequent bilirubin UGT polymorphism UGT1A1*28 are highlighted.

Early clinical studies of inherited hyperbilirubinemias identified the rare and fatal Crigler-Najjar syndromes I and II and the frequent mild form of Gilbert's syndrome. Frequent occurrence of allelic variants is often due to 'balanced polymorphism' [45], i.e. balancing blood bilirubin between high neurotoxic levels and low levels acting as powerful antioxidant [46, for references]. Bilirubin is the final product of heme catabolism, as heme oxygenase cleaves the heme ring to form the water-soluble biliverdin, which is reduced by biliverdin reductase to bilirubin (Fig. 3). Why should mammals have evolved the potentially toxic and insoluble bilirubin? Recently, it was established that bilirubin is oxidized by reactive oxygen species (ROS) to biliverdin which is efficiently reduced back to bilirubin. This amplification cycle establishes a physiologic function of bilirubin as powerful antioxidant [47]. Epidemiologic evidence indicates that homozygous UGT1A1*28 allele carriers with high serum bilirubin exhibit a strong association with lower risk of cardiovascular disease [48]. Bilirubin and bilirubin monoglucuronides produced in extrahepatic tissues are efficiently taken up into hepatocytes by OATP1B1 and converted to bilirubin diglucuronide by UGT1A1.

Gilbert's syndrome in Caucasians is mostly due to an additional TA repeat in the TATA box of UGT1A1 (a promoter polymorphism termed UGT1A1*28), leading to reduced UGT1A1 expression and significantly decreased UGT activity. Liver 
homogenate bilirubin UGT activity in Caucasian carriers of the UGT1A1*28 genotype was only $48 \%$ (ranges $27-75 ; n=6$ ) of the UGT1A1*1 reference genotype (ranges 47 $170 ; n=17$ ) [62]. The frequency of homozygous carriers of UGT1A1*28 in Caucasians is approximately $10 \%$ and the allele frequency 30 to $40 \%$ [46]. Correlation studies between populations expressing UGT1A1*1 and UGT1A1*28 proteins are often used to associate UGT1A1 activity with in vivo responses. Examples include (i) adverse side effects of irinotecan. The topoisomerase inhibitor irinotecan has been approved for standard therapy of colorectal cancer. Its active metabolite SN-38 is mostly metabolized by UGT1A1 and 1A7 [49]. Poor glucuronidators, i.e., carriers of the promoter variant UGT1A ${ }^{\star} 28$ have been suggested to be at higher risk to develop unwanted side effects such as diarrhea [50]. (ii) A strong correlation was observed between UGT1A1-mediated glucuronidation of SN-38 and of T4 [51]; there was a significant trend of decreasing T4 glucuronide levels and expression of UGT1A1*28. Despite low levels of T4 glucuronide in serum, the role of T4 glucuronidation in vivo is supported by alteration of thyroid hormone homeostasis in antiepileptic drug-treated patients [52]. (iii) UGTs such as UGT1A1 and UGT2B7 appear to be involved in homeostasis and further metabobolism of estradiol in endometrium [53]. Estradiol is metabolized to genotoxic 4-hydroxy- or antiproliferative 2-hydroxy-catechol estrogen. Interestingly, reducing the excretion of 2-hydroxyestradiol in carriers of the UGT1A $1 * 28$ allele has been suggested to be responsible for decreased endometrial cancer risk [54]. These three examples may serve to highlight the relevance of in vitro microsomal UGT activity for a variety of in vivo functions.

\subsection{Comparative studies between in vitro enzyme kinetic parameters of UGTs and in vivo drug clearance}

Comparison of in vitro intrinsic clearance of drugs (represented by the enzyme kinetic parameter $V_{\max } / K_{M}$ ) with their hepatic clearance in vivo represents a challenging exercise. In the case of drugs mainly excreted by glucuronidation, it was found that the in vitro intrinsic clearance under-predicts in vivo hepatic clearance $[4,55,56]$. Many factors have been suggested to be responsible for this discrepancy. In addition to general factors such as the nutritional state, the following liver microsomal UGT assay conditions may be relevant: (i) In the case of the antiretroviral drug zidovudine (mainly eliminated via glucuronidation by UGT2B7 [57]) inclusion of the physiologic carbonate buffer or Williams $E$ medium increased $V_{\max }$ and reduced $K_{M}$ in liver 
microsomes, thereby increasing the intrinsic clearance in vitro [58]. Determination of UGT activity in physiologic buffer may better preserve the topology of UGTs and associated proteins in the ER. (ii) Fatty acid-free human serum albumin and bovine serum albumin reduce the $K_{M}$ values for UGT2B7 substrates (but not UGT1A1 and UGT1A6 activities) by sequestering inhibitory long-chain fatty acids released by incubations of human liver microsomes and cell-expressed UGTs. This observation has been termed 'albumin effect' [59]. (iii) As mentioned in chapter 2, rapid hydrolysis of UDP in the ER may explain the lack of product inhibition by UDP [15]. In addition, rapid translocation of glucuronides from ER into the cytoplasm may further decrease product inhibition in vivo. (iiii) Atypical enzyme kinetics, i.e. non-Michaelis-Menten kinetics, is frequently observed in studies of drug glucuronidation and often interpreted by evoking a two site model; in the light of UGT oligomers these sites could be present on separate molecules within the same oligomeric complex [23]. Atypical enzyme kinetics leading to autoactivation could in part be responsible for paradoxical effects observed with the over the counter analgesic drug paracetamol (acetaminophen) [60]. Its metabolism has been intensely investigated, in particular due to its hepatotoxicity in suicidal overdose. Interestingly, paracetamol is a highaffinity substrate for UGT1A6 [60,61]. However, it appears to be mainly conjugated in liver by UGT1A9 (and also by UGT1A1) [60]. Of course, the presently unknown relative abundance of UGT isoforms may also play a role. In conclusion, understanding oligomeric UGTs and the influence of associated proteins may be necessary for the development of generalizable models for the in vitro-in vivo comparison of drug glucuronidation.

\subsection{Role of ER-localized $\beta$-glucuronidase in glucuronide disposition}

Glucuronide disposition may be influenced by ER-localized $\beta$-glucuronidase, possibly involved in futile cycling of glucuronides and hydrolysis of conjugated hormones in target cells. Murine $\beta$-glucuronidase is derived from a single gene but is located in two subcellular sites, the ER and lysosomes. On the way from synthesis in the rough ER to lysosomes part of the enzyme is retained in the lumen of the ER by associating with the carboxylesterase egasyn which contains an ER retention sequence [63-65]. ER-localized $\beta$-glucuronidase has been shown to form tetramers (Fig. 1). Its in vivo activity has been demonstrated in the hydrolysis of bilirubin monoglucuronides [66]. The activity of $\beta$-glucuronidase in the lumen of the ER may lead to futile cycling of 
glucuronides [67], which, however, appears to be limited since ß-glucuronidase activity is low. ER-resident $\beta$-glucuronidase may also be responsible for hydrolysis of hormone and drug glucuronides in cells, examplified by the hydrolysis of T4 glucuronide. T4 is widely used for treatment of hypothyroidism. It is mainly deiodinized to T3 (>70\%) but is also metabolized by conjugation. T4 sulfate is very unstable because sulfation accelerates inner ring deiodination by approximately 200fold [51]. T4 glucuronidation (carried out by UGT1A1 and 1A3) leads to a stable T4 glucuronide which may serve as a mechanism of delivery of T4 into intracellular compartments, as discussed in chapter 5.1 [51,52]. However, the postulated uptake of circulating T4 glucuronide into target cells and its hydrolysis by cellular $\beta$ glucuronidases needs to be further studied. In contrast, lysosomal glucuronidase is involved in the degradation of glycosaminoglycans, synthesized in the Golgi apparatus. Transit of lysosomal glucuronidase from the ER to lysosomes has been reviewed [63].

Hydrolysis of glucuronides is also important for enterohepatic and entero-enteric recirculation of many important drugs including SN-38 (the metabolite of irinotecan (mentioned in chapter 5.1) and in the action of the cholesterol-lowering drug ezetimide which is mainly conjugated by UGT1A1 [68]. It has been suggested that ezetimibe glucuronide represents a storage form for long lasting recycling of the active ezetimibe to the intestinal absorption compartment via the systemic circulation. However, it is unknown to what extent glucuronide hydrolysis contributes to the clearance of drugs mainly eliminated by glucuronidation.

\section{Conclusions}

UDP-glucuronosyltransferases (UGTs) represent major Phase II biotransformation enzymes involved in detoxification of endobiotics such as bilirubin, thyroxin and steroid hormones and xenobiotics including a variety of phytochemicals, environmental pollutants such as benzo[a]pyrene, and many drugs. UGTs represent integral membrane proteins. Accumulating evidence suggests that UGTs operate in ER membranes mostly as homo- and heterodimeric complexes which may fine-tune UGT activity and stabilize the enzyme. Evidence includes recombinant technology [18], cross-linking studies [20], co-immunoprecipitation, and fluorescence resonance technology in live cells [22]. The results of radiation target analysis suggest that tetramers are involved in diglucuronide formation, a finding which, however, needs 
further validation. Orientation of the active site toward the intraluminal space of the ER necessitates a number of transporters (i) for the cofactor UDP-glucuronic acid synthesized in the cytosol, and (ii) for glucuronides between the ER lumen and the cytosol, the latter being insufficiently characterized. Glucuronide hydrolysis by ERlocalized $\beta$-glucuronidase may also require ER-localized glucuronide transporters involved in transport of glucuronides from cytoplasm to ER lumen. Many advances have been made in recent years on the topology and quaternary structure of oligomeric UGTs in ER membranes; but a lot of open questions are remaining. It is hoped that resolution of these questions may help to understand many problems of glucuronide formation and disposition in vivo, for example, under-estimation of in vivo clearance of drugs mainly eliminated by glucuronidation by in vitro enzyme kinetic parameters of UGTs. 


\section{References}

[1] Dutton GJ. Glucuronidation of drugs and other compounds. CRC Press, Boca Raton 1980.

[2] Mackenzie PI, Owens IS, Burchell B, Bock KW, Bairoch A, Belanger A, et al. The UDP-glucuronosyltransferase gene superfamily: recommended nomenclature based on evolutionary divergence. Pharmacogenetics 1997;7:255-69.

[3] Tukey RT, Strassburg C. Human UDP-glucuronosyltransferases: metabolism, expression, and disease. Ann Rev Pharmacol Toxicol 2000;40:581-616.

[4] Miners JO, Smith PA, Sorich MJ, McKinnon RA, Mackenzie PI. Prediction of human drug glucuronidation parameters: application of in vitro and in silico modeling approaches. Ann Rev Pharmacol Toxicol 2004;44:1-25.

[5] Mackenzie PI, Bock KW, Burchell B, Guillemette C, Ikushiro S, lyanagi T, et al. Nomenclature update for the mammalian UDP glycosyltransferase (UGT) gene superfamily. Pharmacogenetics Genomics 2005;15:677-85.

[6] König J, Nies AT, Cui Y, Leier I, Keppler D. Conjugate export pumps of the multidrug resistance protein (MRP) family: localization, substrate specificity, and MRP2-mediated drug resistance. Biochim Biophys Acta 1999;1461:377-94.

[7] König J, Sithel A, Gradhand U, Fromm MF. Pharmacogenomics of human OATP transporters. Naunyn-Schmideberg's Arch Pharmacol 2006;372:432-43.

[8] Köhle C, Bock KW. Coordinate regulation of drug-metabolizing enzymes and conjugate transporters by the Ah receptor, pregnane $X$ receptor, and constitutive androstane receptor. Biochem Pharmacol 2009; in press.

[9] Kobayashi T, Sleeman JE, Coughtrie MWH, Burchell B. Molecular and functional characterization of microsomal UDP-glucuronic acid uptake by members of the nucleotide sugar transporter (NST) family. Biochem J 2005;400:281-9.

[10] Bossuyt X, Blanckaert N. Mechanism of stimulation of microsomal UDPglucurosyltransferase by UDP-N-acetylglucosamine. Biochem J 1995;305:321-8.

[11] Miley MJ, Zielinska AK, Keenan JE, Bratton SM, Radominska-Pandya A, Redinbo MR. Crystal structure of the cofactor-binding domain of the human Phase II 
drug-metabolizing enzyme UDP-glucuronosyltransferase 2B7. J Mol Biol 2007;369:498-511.

[12] Ouzzine M, Magdalou J, Burchell B, Fournel-Gigleux S. An internal signal sequence mediates the targeting and retention of the UDP-glucuronosyltransferase 1A6 to the endoplasmic reticulum. J Biol Chem 1999;274:31401-9.

[13] Patana AS, Kurkela M, Finel M, Goldman A. Mutation analysis in UGT1A9 suggests a relationship between substrate and catalytic residues in UDPglucuronosyltransferases. Protein Engineer Design Selection 2008;1-7.

[14] Finch SA, Slater TF, Stier A. Nucleotide metabolism by microsomal UDPglucuronosyltransferase and nucleoside diphosphatase as determined by ${ }^{31} \mathrm{P}$ nuclear-magnetic-resonance spectroscopy. Biochem J 1979;177:925-30.

[15] Fujiwara R, Nakajima M, Yamanaka H, Katoh M, Yokoi T. Product inhibition of UDP-glucuronosyltransferase (UGT) enzymes by UDP obfuscates the inhibitory effects of UGT substrates. Dug Metab Disp 2008;36:361-7.

[16] Battaglia E, Gollan J. A unique multifunctional transporter translocates estradiol-17ß- glucuronide in rat liver microsomal vesicles. J Biol Chem 2001;276:23492-8.

[17] Csala M, Staines AG, Banhegyi G, Mandl J, Coughtrie MWH, Burchell B. Evidence for multiple glucuronide transporters in rat liver microsomes. Biochem Pharmacol 2004;68:1353-62.

[18] Meech R, Mackenzie PI. UDP-glucuronosyltransferase, the role of the amino terminus in dimerization. J Biol Chem 1997;272:26913-7.

[19] Ikushiro S, Emi Y, lyanagi T. Protein-protein interactions between UDPglucuronosyltransferase isozymes in rat hepatic microsomes. Biochemistry 1997; 36:7154-61.

[20] Ghosh SS, Sappal BS, Kalpana GV, Lee SW, Chowdhury JR, Chowdhury NJ. Homodimerization of human bilirubin-uridine-diphosphate glucuronosyltransferase-1 (UGT1A1) and its functional implications. J Biol Chem 2001;276:42108-15. 
[21] Kurkela M, Garcia-Horsman JA, Luukkanen L, Mörsky S, Taskinen J, Baumann M, et al. Expression and characterization of recombinant human UDPglucuronosyltransferases (UGTs). J Biol Chem 2003;278:3536-44.

[22] Operana TN, Tukey RH. Oligomerization of the UDP-glucuronosyltransferase 1A proteins. J Biol Chem 2007;282:4821-9.

[23] Finel M, Kurkela M. The UDP-glucuronosyltransferases as oligomeric enzymes. Current Drug Metab 2008;9:70-6.

[24] Kurkela M, Patana AS, Mackenzie PI, Court MH, Tate CG, Hirvonen J, et al. Interaction with other UDP-glucuronosyltransferases attenuate the consequences of the Y485D mutation on the activity and substrate affinity of UGT1A6.

Pharmacogenetics Genomics 2007;17:115-26.

[25] Fujiwara R, Nakajima M, Yamanaka H, Katoh M, Yokoi T. Interactions between human UGT1A1, UGT1A4, and UGT1A6 affect their enzymatic activities. Drug Metab Disp 2007;35:1781-7.

[26] Krishnaswamy S, Duan SX, Von Moltke LL, Greenblatt DJ, Court MH. Validation of serotonin (5-hydroxytryptamine) as an in vitro substrate probe for human UDP-glucuronosyltransferase (UGT) 1A6. Drug Metab Disp 2003;31:133-9.

[27] Girard H, Levesque E, Bellemare J, Journault K, Caillier B, Guillemette C. Genetic diversity at the UGT1 locus is amplified by a novel 3 ' alternative splicing mechanism leading to nine additional UGT1A proteins that act as regulators of glucuronidation activity. Pharmacogenetics Genomics 2007;17:1077-89

[28] Kempner ES, Fleischer S. Radiation inactivation of membrane components and molecular mass determination by target analysis. Methods Enzymol 1989;172:1241-439.

[29] Kempner ES. Novel predictions from radiation target analysis. TIBS 1993;18:236-9.

[30] Vessey DA, Kempner ES. In situ structural analysis of microsomal UDPglucuronosyltransferases by radiation inactivation. J Biol Chem 1989;264:6334-8. 
[31] Peters WHM, Jansen PLM, Nauta $H$. The molecular weights of UDPglucuronosyltransferase determined with radiation-inactivation analysis. J Biol Chem 1984;259:11701-6.

[32] Udomuksorn W, Elliot DJ, Lewis BC, Mackenzie PI, Yoovathaworn K, Miners JO. Influence of mutations associated with Gilbert and Crigler-Najjar type II syndromes on the glucuronidation kinetics of bilirubin and other UDPglucuronosyltransferase 1A substrates. Pharmacogenetics Genomics 2007;17:101729.

[33] Lilienblum W, Bock-Hennig BS, Bock KW. Protection against toxic redox cycles between benzo(a)pyrene-3,6-quinone and its quinol by 3-methylcholanthreneinducible formation of the quinol mono- and diglucuronide. Mol Pharmacol 1985;27:451-8.

[34] Bock KW, Gschaidmeier H, Seidel A, Baird S, Burchell B. Mono- and diglucuronide formation from chrysene and benzo(a)pyrene phenols by 3methylcholanthrene-inducible phenol UDP-glucuronosyltransferase (UGT1A1). Mol Pharmacol 1992;42:613-8.

[35] Bock KW, Raschko FT, Gschaidmeier H, Seidel A, Oesch F, Grove AD, et al. Mono- and diglucuronide formation from benzo[a]pyrene and chrysene diphenols by AHH-1 cell-expressed UDP-glucuronosyltransferase UGT1A7. Biochem Pharmacol 1999;57:653-6.

[36] Lorentzen RJ, Ts'o POP. Benzo(a)pyrenedione/benzo(a)pyrenediol oxidationreduction couples and the generation of reactive reduced molecular oxygen. Biochemistry 1977;16:1467-73.

[37] Lorentzen RJ, Lesco SA, McDonald K, Ts'o POP. Toxicity of metabolic benzo(a)pyrenediones to cultured cells and the dependence upon molecular oxygen. Cancer Res 1979;39:3194-8.

[38] Bevan DR, Sadler VM. Quinol diglucuronides are predominant metabolites found in bile of rats following intratracheal instillation of benzo(a)pyrene. Carcinogenesis 1992;13:403-7. 
[39] Yang Y, Griffiths WJ, Midtvedt T, Sjövall J, Rafter F, Gustafsson JA.

Characterization of conjugated metabolites of benzo[a]pyrene in germ-free rat urine by liquid chromatography/electrospray tandem mass spectrometry. Chem Res Toxicol 1999;12:1182-9.

[40] Gschaidmeier $\mathrm{H}$, Bock KW. Radiation inactivation analysis of microsomal UDP-glucuronosyltransferases catalyzing mono- and diglucuronide formation of 3,6dihydroxybenzo[a]pyrene and 3,6-dihydroxychrysene. Biochem Pharmacol 1994;48:1545-9.

[41] Tukey RH, Tephly TR. Purification and properties of rabbit liver estrone and pnitrophenol UDP-glucuronyltransferases. Arch Biochem Biophys 1981;209:565-78.

[42] Bock KW, Lilienblum W, Ullrich D, Fischer G. Differential induction of UDPglucuronosyltransferases and their 'permanent induction' in pre-neoplastic rat liver. Biochem Soc Transact 1984;12:55-58.

[43] Hartung T. Mono- und Diglucuronidbildung von Benzpyren-3,6-chinol durch Lebermikrosomen von Ratte and Mensch. Thesis, Med Faculty, University of Tübingen, 1992.

[44] Bock KW, Köhle C. UDP-glucuronosyltransferase 1A6: structural, functional, and regulatory aspects. Methods Enzymol 2005;400:57-75.

[45] Beutler E, Gelbart T, Demina A. Racial variability in the UDPglucuronosyltransferase 1 (UGT1A1) promoter: a balanced polymorphism for regulation of bilirubin metabolism? Proc Natl Acad Sci USA 1998;95:8170-4.

[46] Köhle C, Möhrle B, Münzel PA, Schwab M, Wernet D, Badary OA, et al. Frequent co-occurrence of the TATA box mutation associated with Gilbert's syndrome (UGT1A $\left.{ }^{*} 28\right)$ with other polymorphisms of the UDPglucuronosyltransferase-1 locus (UGT1A6*2 and UGT1A7*3) in Caucasians and Egyptians. Biochem Pharmacol 2003;65:1521-7.

[47] Baranano DE, Rao M, Ferris CD, Snyder SH. Biliverdin reductase: a major physiologic cytoprotectant. Proc Natl Acad Sci USA 2002;99:16093-8. 
[48] Lin JP, O'Donnell CJ, Schwaiger JP, Cupples LA, Lingenhel A, Hunt SC, et al. Association between UGT1A1*28 allele, bilirubin levels, and coronary heart disease in the Framingham Heart Study. Circulation 2006;114:1476-81.

[49] Tukey RH, Strassburg CP, Mackenzie PI. Pharmacogenomics of human UDPglucuronosyltransferases and irinotecan toxicity: Mol Pharmacol 2002;62:446-50.

[50] Ando Y, Saka H, Ando M, Sawa T, Muro K, Ueoka H, et al. Polymorphisms of UDP-glucuronosyltransferase gene and irinotecan toxicity: a pharmacogenetic analysis. Cancer Res 2000;60:6921-6.

[51] Yoder Graber AL, Ramirez J, Innocenti F, Ratain MJ. UGT1A1²8 genotype affects in-vitro glucuronidation of thyroxine in human livers. Pharmacogenetics Genomics 2007;17:619-27.

[52] Benedetti MS, Whomsley R, Baltes E, Tonner F. Alteration of thyroid hormone homeostasis by antiepileptic drugs in humans: involvement of glucuronosyltransferase induction. Eur J Clin Pharmacol 2005;61:863-72.

[53] Lepine J, Bernard O, Plante M, Tetu B, Pelletier G, Labri F, et al. Specificity and regioselectivity of the conjugation of estradiol, estrone, and their catecholestrogen and methoxyestrogen metabolites by human uridine-diphosphoglucuronosyltransferases expressed in endometrium. J Clin Endocrinol Metab 2004;89:5222-32.

[54] Duguay Y, McGrath M, Lepine J, Gagne JF, Hankinson SE, Colditz GA, et al. The functional UGT1A1 polymorphism decreases endometrial cancer risk. Cancer Res 2004;64:1202-7.Cancer Res 2004;64:1202-7.

[55] Soars MG, Burchell B, Riley RJ. In vitro analysis of human drug glucuronidation and prediction of in vivo metabolic clearance. J Pharmacol Exp Toxicol 2002;301:382-90.

[56] Miners JO, Knights KM, Houston JB, Mackenzie PI. In vitro-in vivo correlation for drugs and other compounds eliminated by glucuronidation in humans: pitfalls and promises. Biochem Pharmacol 2006;71:1531-9.

[57] Court MH, Krishnaswamy S, Hao Q, Duan SX, Patten CJ, Von Moltke L, et al. Evaluation of 3'-azido-3'-deoxythymidine, morphine, and codeine as probe substrates 
for UDP-glucuronosyltransferase 2B7 (UGT2B7) in human liver microsomes: specificity and influence of the UGT2B7 ${ }^{\star} 2$ polymorphism. Drug Metab Disp 2003;31:1125-33.

[58] Engtrakul JJ, Foti RS, Strelevitz TJ, Fisher MB. Altered AZT (3'-azido-3'deoxythymidine) glucuronidation kinetics in liver microsomes as an explanation for underprediction of in vivo clearance: comparison to hepatocytes and effect of incubation environment. Drug Metab Disp 2005;33:1621-7.

[59] Rowland A, Knights KM, Mackenzie PI, Miners JO. The "albumin effect" and drug glucuronidation: bovine serum albumin and fatty acid-free human serum albumin enhance the glucuronidation of UDP-glucuronosyltransferase (UGT) 1A9 substrates but not UGT1A1 and UGT1A6 activities. Drug Metab Disp 2008;36:105662.

[60] Court MH, Duan SX, von Moltke LL, Greenblatt J, Patten CJ, Miners JO, et al. Interindividual variability in acetaminophen glucuronidation by human liver microsomes: identification of relevant acetaminophen UDP-glucuronosyltransferase isoforms. J Pharmacol Exp Ther 2001;299:998-1006.

[61] Bock KW, Forster A, Gschaidmeier H, Brück M, Münzel P, Scharek W, et al. Paracetamol glucuronidation by recombinant rat and human phenol UDPglucuronosyltransferases. Biochem Pharmacol 1993;45:1809-14.

[62] Raijmakers MTM, Jansen PLM, Steegers EAP, Peters WHM. Association of human liver bilirubin UDP-glucuronosyltransferase activity with a polymorphism in the promoter region of the UGT1A1 gene. J Hepatol 2000;33:348-51.

[63] Swank RT, Novak EK, Zhen L. Regulation of the subcellular localization and expression of glucuronidase. Handbook of Experimental Pharmacology 1994,112;131-60.

[64] Zhen L, Rusiniak ME, Swank RT. The $\beta$-glucuronidase propeptide contains a serpin-related octamer necessary for complex formation with egasyn esterase and for retention within the endoplasmic reticulum. J Biol Chem 1995;270:11912-20.

[65] Islam MR, Waheed A, Shah GN, Tomatsu S, Sly WS. Human egasyn binds beta-glucuronidase but neither the esterase active site of egasyn nor the $C$ terminus 
of beta-glucuronidase in involved in their interaction. Arch Biochem Biophys 1999;372:53-61.

[66] Whiting JF, Narciso JP, Chapman V, Ransil BJ, Swank RT, Gollan JL. Deconjugation of bilirubin-IXa glucuronides: a physiologic role of hepatic microsomal ß-glucuronidase. J Biol Chem 1993;268:23197-201.

[67] Kauffman FC. Regulation of drug conjugate production by futile cycling in intact cells. Handbook of Experimental Pharmacology 1994;112:245-55.

[68] Oswald S, Haenisch S, Fricke C, Sunhop T, Remmler C, Giessmann, et al. Intestinal expression of P-glycoprotein (ABCB1), multidrug resistance associated protein 2 ( $A B C C 2$ ), and uridine diphosphate-glucuronosyltransferase $1 \mathrm{~A} 1$ predicts the disposition and modulates the effects of cholesterol absorption inhibitor ezetimibe in humans. Clin Pharmacol Ther 2006:79.206-17. 


\section{Figure legends}

Fig. 1. Schematic model of ER-localized UGT oligomers, $\beta$-glucuronidase and functionally associated transporters. UGTs consist of the N-terminal aglycone (X$\mathrm{OH}$ )-binding half of the monomer and the UDPGA-binding C-terminus with transmembrane segment and cytoplasmic tail (dark). Accumulating evidence suggests that UGTs are functional as dimers in monoglucuronide formation. Two dimers may interact to form a tetramer in diglucuronide formation (see text). Tetrameric $\beta$-glucuronidase retained in ER membranes by the carboxylesterase egasyn [63] may be involved in futile cycling of glucuronides and the hydrolysis of hormone glucuronides in target cells (discussed in chapter 5.3). The luminal orientation of UGTs and $\beta$-glucuronidase requires the action of additional proteins such as nucleotide sugar transporters (NSTs), transporting the cofactor UDPGA to the lumen of the ER, and multiple organic anion transporters in ER membranes $\left(A T_{E R}\right)$ transporting glucuronides to the cytosol or back into the ER lumen. It is tempting to speculate that glucuronide transporters may be localized in the proximity of UGTs to prevent accumulation of glucuronides in the lumen.

Fig.2. (A) Structures of benzo[a]pyrene (BaP)- and chrysene-3,6-quinols. (B) Role of glucuronidation in detoxification of BaP quinones (Q). QOH, quinols; QOGA and $\mathrm{QO}(\mathrm{GA})_{2}$, quinol monoglucuronides and diglucuronide, respectively; NQO1, $\mathrm{NAD}(\mathrm{P}) \mathrm{H}$ quinone oxidoreductase-1, which bypasses the semiquinone step; GSTs, glutathione S-transferases.

Fig.3. Scheme of heme catabolism to bilirubin and its diglucuronide in hepatocytes and the physiologic role of bilirubin as antioxidant. Bilirubin can be oxidized by ROS to biliverdin which is efficiently reduced back to bilirubin by biliverdin reductase. This magnifying cycle represents the basis for the role of bilirubin as antioxidant [47]. 
Table 1. Formation of moglucuronides (MG) and diglucuronides (DG) of benzo[a]pyrene (BaP)- and chrysene-3,6-quinol. For calculation of the MG/DG ratio the sum of the two MGs are used. Data for BaP-3,6-quinol UGT activity in microsomes and expressed UGT1A6 were taken from [33] and [34], respectively; data for chrysene-3,6-quinol UGT activity in liver microsomes of untreated controls and 3-MC-treated rats and expressed UGT1A6 were taken from [34] and for expressed UGT1A7 from [35]. MG/DG ratios are operationally used as inverse parameters for the efficiency of diglucuronide formation.

\begin{tabular}{lllll}
\hline Substrate & \multicolumn{3}{c}{ UGT activity (nmol/min/mg protein) } \\
& $\begin{array}{l}\text { Liver microsomes } \\
\text { Control }\end{array}$ & 3-MC & rUGT1A6 & rUGT1A7 \\
\hline $\begin{array}{l}\text { BaP-3,6- } \\
\text { quinol }\end{array}$ & & & & \\
MG & 5.8 & 60 & 1.5 & 0.75 \\
DG & 0.17 & 6.4 & 0.09 & 0.09 \\
\hline MG/DG & 34 & 9 & 17 & 8 \\
\hline Chrysene- & & & & \\
3,6-quinol & & & & \\
MG & 2.8 & 20.8 & 0.03 & 0.057 \\
DG & 0.02 & 6.2 & - & 0.033 \\
\hline MG/DG & 140 & 3 & - & 2 \\
\hline
\end{tabular}




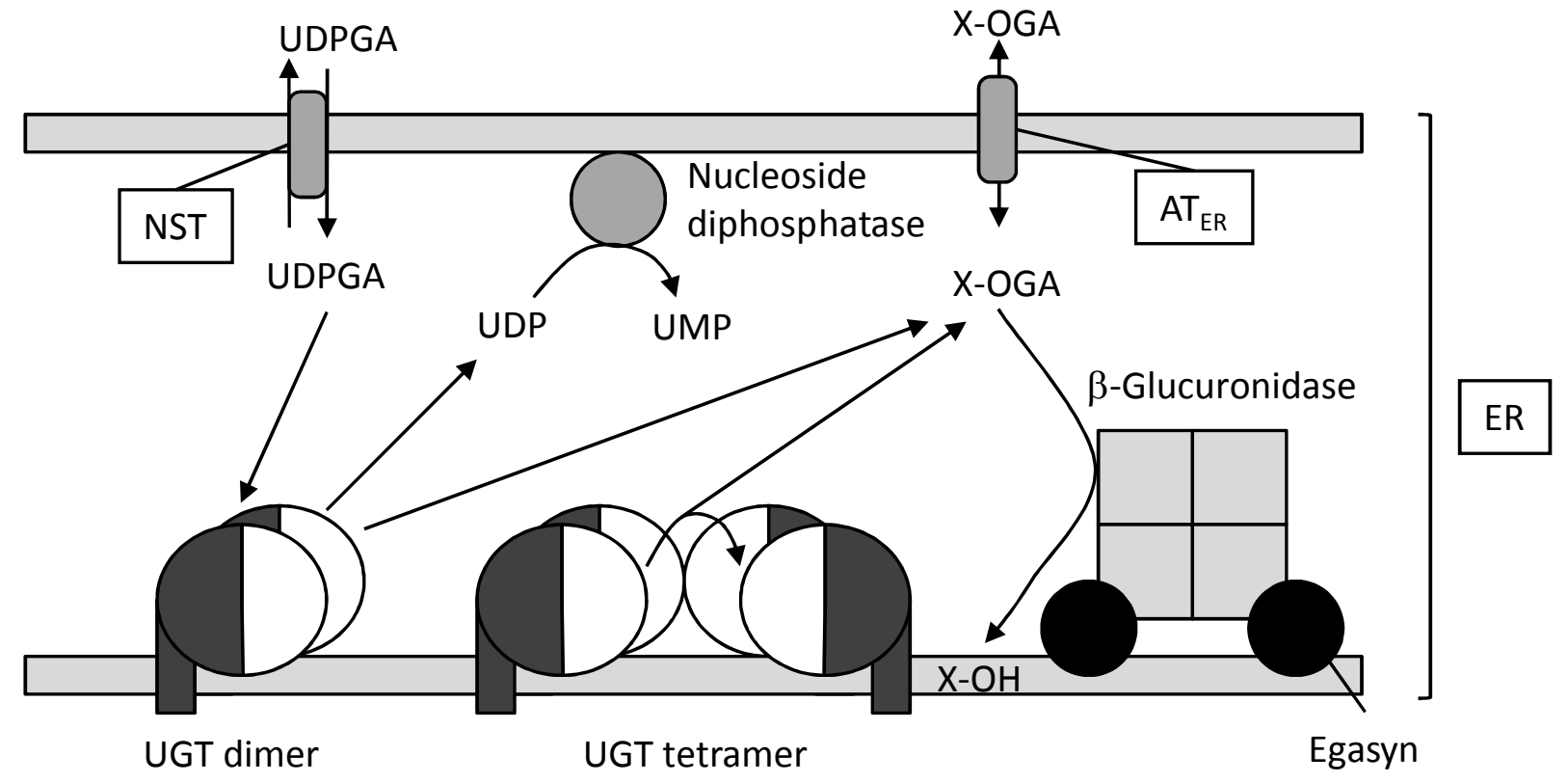


A
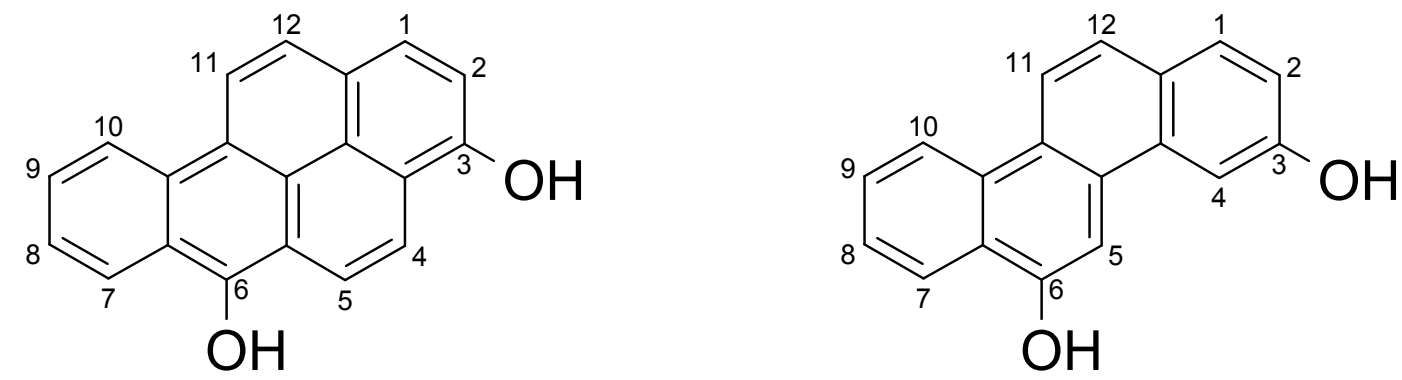

B

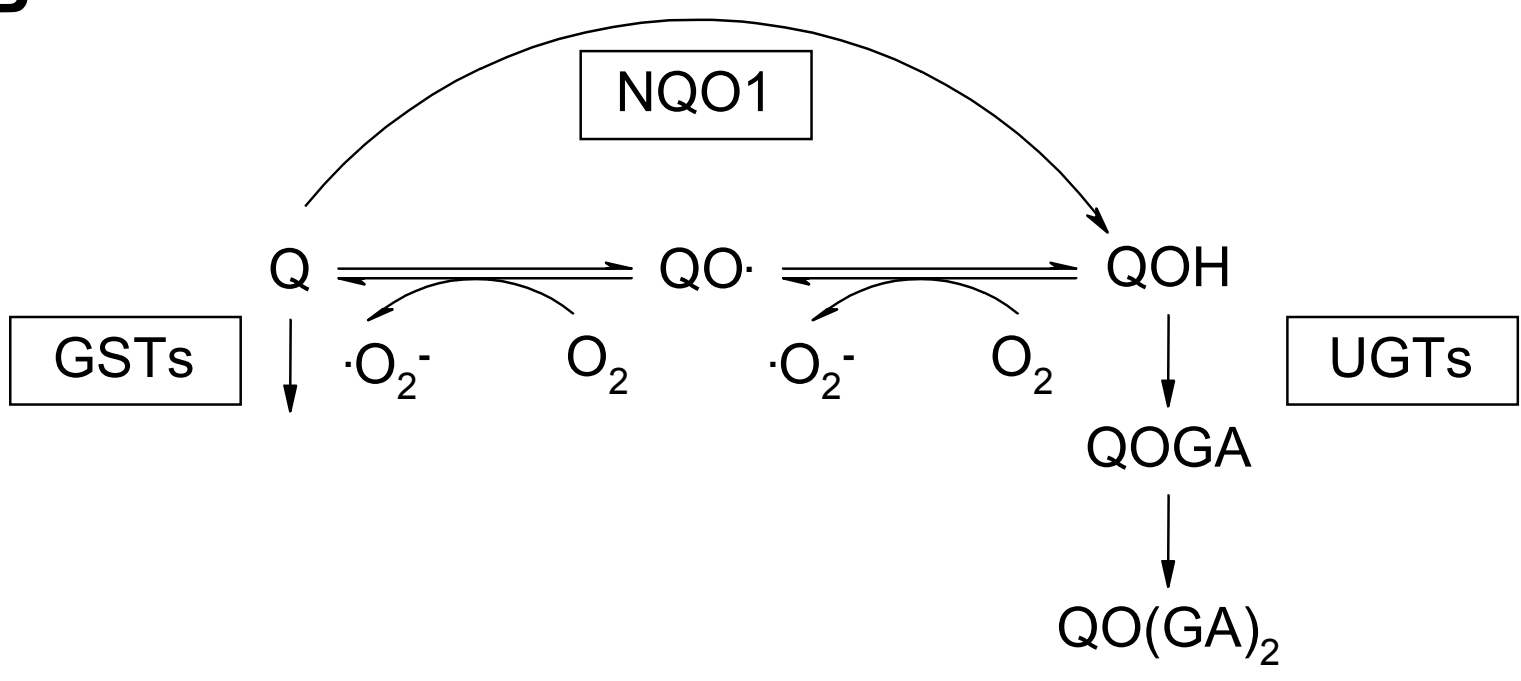




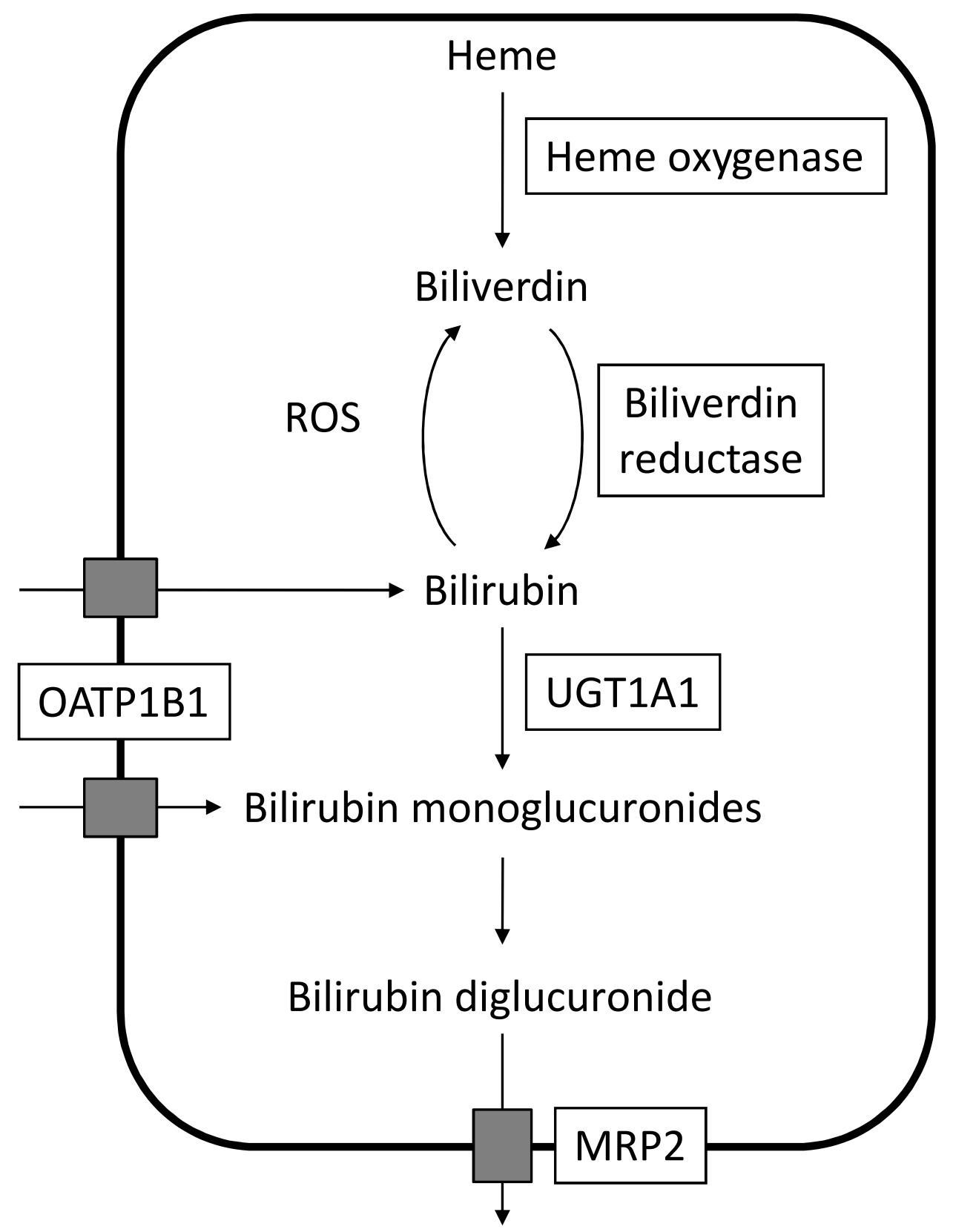


UDP glucuronosyltransferases are functional as oligomers. The intraluminal orientation of the active site in endoplasmic reticulum membranes necessitates a number of transporters for the cofactor UDP-glucuronic acid and glucuronides. 


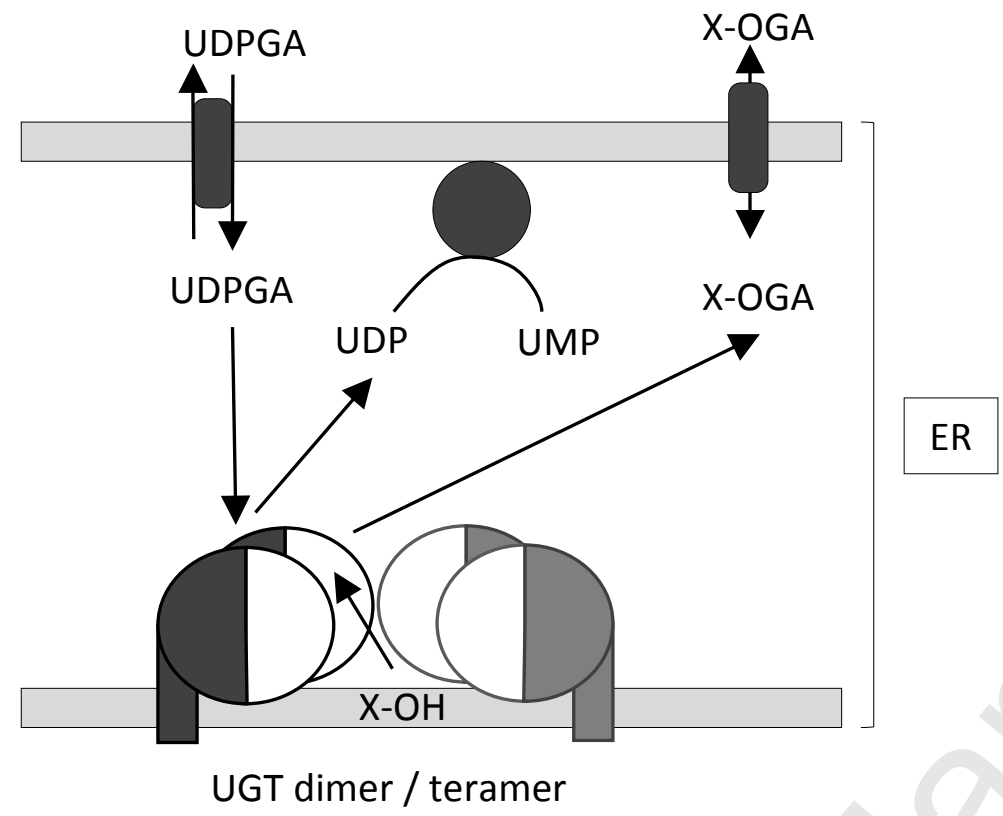

Page 26 of 26 